\title{
P Wave Axis
}

National Cancer Institute

\section{Source}

National Cancer Institute. P Wave Axis. NCI Thesaurus. Code C118164.

A numerical representation of the electrocardiographic vector assessed at maximum deviation of the $\mathrm{P}$ wave from the isoelectric baseline, usually reported for the frontal plane. (CDISC) 